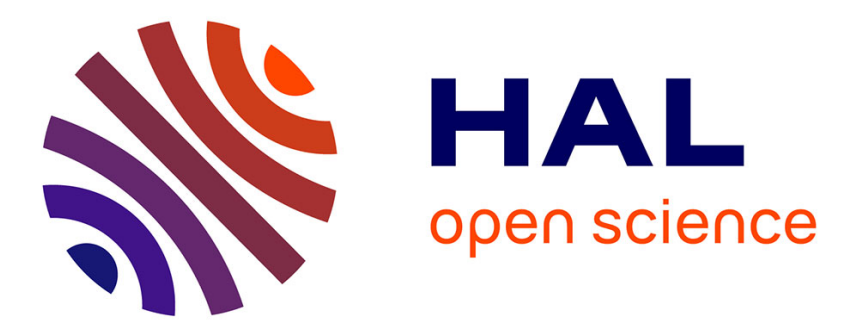

\title{
Mechanism of Integrating Force and Vibrotactile Cues for 3D User Interaction within Virtual Environments
}

\author{
Aïda Erfanian, Stanley Tarng, Yaoping Hu, Jérémy Plouzeau, Frédéric
}

Merienne

\section{- To cite this version:}

Aïda Erfanian, Stanley Tarng, Yaoping Hu, Jérémy Plouzeau, Frédéric Merienne. Mechanism of Integrating Force and Vibrotactile Cues for 3D User Interaction within Virtual Environments. IEEE Virtual Reality, Mar 2017, Los Angeles, United States. pp.257-258, 10.1109/VR.2017.7892274 . hal01789058

\section{HAL Id: hal-01789058 \\ https://hal.science/hal-01789058}

Submitted on 9 May 2018

HAL is a multi-disciplinary open access archive for the deposit and dissemination of scientific research documents, whether they are published or not. The documents may come from teaching and research institutions in France or abroad, or from public or private research centers.
L'archive ouverte pluridisciplinaire HAL, est destinée au dépôt et à la diffusion de documents scientifiques de niveau recherche, publiés ou non, émanant des établissements d'enseignement et de recherche français ou étrangers, des laboratoires publics ou privés. 


\section{Mechanism of Integrating Force and Vibrotactile Cues for 3D User Interaction within Virtual Environments}

\author{
Aida Erfanian* Stanley Tarng* Yaoping $\mathrm{Hu}^{*}$ \\ * Dept. of Electrical and Computer Engineering \\ Schulich School of Engineering \\ University of Calgary, CANADA
}

\author{
Jérémy Plouzeau ${ }^{\dagger} \quad$ Frédéric Merienne $^{\dagger}$ \\ † LE2I UMR6306 \\ Arts et Métiers \\ CNRS University, FRANCE
}

\begin{abstract}
Proper integration of sensory cues facilitates 3D user interaction within virtual environments (VEs). Studies showed that the integration of visual and haptic cues follows maximum likelihood estimation (MLE). Little effort focuses however on the mechanism of integrating force and vibrotactile cues. We thus investigated MLE's suitability for integrating these cues. Within a VE, human users undertook 3D interaction of navigating a flying drone along a high-voltage transmission line for inspection. The users received individual force or vibrotactile cues, and their combinations in collocated and dislocated settings. The users' task performance including completion time and accuracy was assessed under each individual cue and setting. The presence of the vibrotactile cue promoted a better performance than the force cue alone. This agreed with the applicability of tactile cues for sensing 3D surfaces, herein setting a baseline for using MLE. The task performance under the collocated setting indicated a degree of combining the individual cues. In contrast, the performance under the dislocated setting was alike under the individual vibrotactile cue. These observations imply a possible role of MLE in integrating force and vibrotactile cues for 3D user interaction within VEs.
\end{abstract}

Index Terms: H.5.1 [Multimedia Information Systems]: Artificial, augmented and virtual realities; H.5.2 [User Interfaces]: Haptic I/O.

\section{INTRODUCTION}

Virtual environments (VEs) need to provide human users with multi-sensory feedback [3]. As user tasks within VEs become progressively demanding in precision and accuracy, it is necessary to integrate multi-sensory feedback for meeting the demand. Each human sensory modality responds to various cues, which stimulate certain sub-categories of the modality. For the modality of haptics, sub-categorical cues include kinesthetic force and pressure, as well cutaneous textures of surfaces (e.g., vibration, etc.) $[6,12]$. Such cues have been applied to enhance user interaction within VEs [11]. Force and vibrotactile cues are often used to aid the users in manipulating objects, along with visual information of the objects.

When manipulating physical objects, the users expect feedbacks in contact with the objects. That is, force and vibrotactile cues are collocated to cause the users' cognitive responses for their action [1]. Due to design restriction and implementation of haptic devices, force and vibrotactile cues could be collocated or dislocated for 3D user interaction within VEs $[13,15]$. Proper integration of both cues is therefore paramount for creating intuitive VEs and

\footnotetext{
* email: \{aerfania, stanley.tarng, huy\}@ucalgary.ca

$\dagger$ email: \{jeremy.plouzeau, frederic.merienne\}@ensam.eu
}

facilitating 3D interaction. Existing reports on multi-sensory integration have focused on cues of the visual and haptic modalities $[5,14]$, disparity and texture cues of the visual modality [8], and force and position cues of the haptic modality [4]. These integrations had collocated cues and followed maximum likelihood estimation (MLE) [5]. However, little effort is devoted to the mechanism of integrating force and vibrotactile cues. We thus undertook a human study to investigate the suitability of MLE for integrating force and vibrotactile cues of the haptic modality.

\section{EMPIRICAL STUDY}

Using the Unity game engine, we developed a VE for a 3D interactive task. The VE employed one motor of a VibroTac bracelet (SENSODRIVE Gmbh, Germany) and a PHANToM Omni device (Geomagic Inc., USA) to provide vibrotactile and force cues, respectively. While a participant (the user) used his/her right hand to hold the device's stylus, the bracelet could be collocated with the device's stylus on the right hand or dislocated on his/her right forearm. For each participant, a pair of ear plugs blocked out the noise generated by the bracelet. An E4 wristband (Empatica Inc., Italy) on the left wrist of the participant monitored his/her physiological signals. On a wall-sized screen, the VE displayed the stereoscopic scene of a high-voltage power transmission line located in an inaccessible mountainous region. The line was curved downwards between two supporting towers due to the gravity. The participant viewed the scene through a pair of passive stereo goggles and used the device's stylus to fly a drone along the curved line. A camera on the front of the drone allowed the participant to view the scene from the drone's perspective. A rigid arm attached to the bottom of the drone had a clamp at its distal end. The clamp covered the line for sensing defects. The defects were minuscular for visual differentiation and randomly distributed on the line. The participant declared a defect by pressing down both buttons on the device's stylus.

Ten male participants $(26.78 \pm 5.77$ years old, and naïve to the purpose of the study) took part in the study. A pre-screening verified each participant to be right-handed, with normal (or correct-to-normal) vision including stereo acuity and color recognition. During the pre-screening, the recorded physiological data of the E4 wristband provided a baseline for each participant [2]. The study had an ethics approval by the University of Calgary.

The task of the participant was to inspect the defects on the line, by using the stylus of the device to fly the drone and slide the clamp along the line. A continuous force, $\vec{F}_{c}$, tangentially along the line facilitated the participant to govern the flying drone. With a constant magnitude of $0.5 \mathrm{~N}$, the force updated dynamically its direction with respect to the location of the clamp on the line. Any defect was signaled via the individual or combined force and vibrotactile cues, which formed the following 5 haptic profiles:

- F_only: An individual force cue had a constant magnitude of $0 . \overline{6} \mathrm{~N}$ to last $1.0 \mathrm{~s}$. The cue was $20 \%$ stronger than $\vec{F}_{c}(>15 \%$ - a just noticeable difference [10]) but with the same direction. 
- V_co: An individual vibrotactile cue was a vibration at 200 $\mathrm{Hz}$. This frequency was within the sensing range of the humans [15]. The cue lasted $1.0 \mathrm{~s}$ on the right hand.

- V_dis: An individual vibrotactile cue had the same vibration as V_co, but was located on the right forearm.

- FV_co: A collocated setting of the concurrent F_only and $\mathrm{V}$ co profiles on the right hand.

- FV_dis: A dislocated setting of the concurrent F_only and V_dis profiles on the right hand and forearm, respectively.

Each of these haptic profiles corresponded to one testing block.

There was one practice block before each testing block. During each practice block, the participant learnt the task by utilizing an individual or combined cues. The locations of 15 defects differed among all practice and testing blocks. After each block, the participant answered two questionnaires: one on cybersickness (SSQ) [9]; and another on the subjective data of each participant's perceived usefulness $(U s f)$, effectiveness $(E f f)$, pleasure $(P l s)$, and workload $(W l d)$. The perceived workload was devised by using the NASA task load index [7]. As objective data, our VE application logged his/her task performance including task completion time $(T C T)$ and accuracy in identifying defects $(A c c)$. The participant spent averagely 1.5 hours in the study. The testing blocks were counterbalanced for all participants in a within-subject design.

\section{Results AND Discussion}

None of the participants had cybersickness, according to their SSQ responses and the consistency between their physiological baseline and recoded data. There were no outliers among the participants, because each of them detected much more than 7 defects. All objective and subjective data were analyzed using one-way repeated measures analysis of variance (ANOVA). Normality tests were conducted to verify the eligibility of these data for ANOVA analyses. As summarized in Table 1, ANOVA analyses on TCT, Usf and Wld revealed no significant difference among all testing blocks. In contrast, a significant differentiability was observed for each of Acc, Pls and Eff. Post-hoc Bonferroni tests indicated that, for $A c c, 3$ pairs of the blocks (F_only vs. V_co; F_only vs. V_dis; and $\mathrm{F}$ _only vs. FV_dis) were differentiable. For $\overline{P l}$ s and Eff, there was a significant difference between the $\mathrm{F}$ only block and every other block. That is, the vibrotactile cue promoted a better Acc, Eff, and $P l s$ than the force cue alone. This agreed with the observations on tactile cues for sensing 3D surfaces [11], establishing a baseline for examining the integration of force and vibrotactile cues.

The integration of both cues was examined on $A c c$ by using MLE [14], because TCT was non-differentiable. Each testing block yielded an experimentally estimated Gaussian distribution, according to the MLE's rules. Each distribution was characterized by its magnitude $(M)$, mean $(\mu)$, and standard deviation $(\sigma)$.

Under the collocated setting, the Gaussian distribution of the FV_co block overlapped evenly with those of both V_co and F only blocks. The $\mu$ of the FV co block was very similar to that of a predicted distribution, which combined theoretically both cues by the rules of MLE. This is much in the same way as multi-sensory integration of visual and haptic cues [5]. However, the combination of both force and vibrotactile cues is not optimal, due to the different $M$ and $\sigma$ between the FV_co block and its prediction.

Under the dislocated setting, the Gaussian distribution of the FV_dis block overlapped that of the $\mathrm{V}$ dis block much more than the $\overline{\mathrm{F}}$ only block. The $\mu$ of the FV dis block was within $1 \sigma$ from the $\mu$ of the V_dis block, but far beyond $1 \sigma$ from the $\mu$ of the F_only block. The $\bar{M}$ and $\sigma$ of the FV dis block were the highest and narrowest among all three blocks, followed by those of the V_dis block and the $\mathrm{F}$ only block in sequence. Moreover, the $\mu$ of the predicted distribution for combing both cues was much smaller than that of the FV_dis block, but with the similar $M$ and $\sigma$. The role of the individual force cue is not ignored entirely, as the
Table 1: Means and standard deviations of the objective and subjective data; and ANOVA results among all testing blocks.

\begin{tabular}{|c|c|c|c|c|c|c|c|}
\hline \multirow[b]{2}{*}{$\begin{array}{c}\text { Data } \\
\text { (Objective/ } \\
\text { Subjective) }\end{array}$} & \multicolumn{5}{|c|}{ Testing Blocks $(\mu \pm \sigma)$} & \multicolumn{2}{|c|}{ ANOVA } \\
\hline & $\underset{\text { only }}{\mathbf{F}_{-}}$ & $\begin{array}{l}V_{-} \\
\text {co }\end{array}$ & $\begin{array}{l}\mathrm{V}_{-} \\
\text {dis }\end{array}$ & $\begin{array}{c}\mathbf{F V} \\
\text { co }\end{array}$ & $\begin{array}{c}\mathrm{FV}_{-} \\
\mathrm{dis}\end{array}$ & 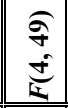 & 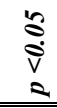 \\
\hline $\begin{array}{l}T C T(\mathrm{~s}) \\
\end{array}$ & $4.1 \pm 0.6$ & $4.2 \pm 0.9$ & $4.2 \pm 0.8$ & $4.9 \pm 2.1$ & $4.0 \pm 0.8$ & 1.39 & - \\
\hline $\operatorname{Acc}(\%)$ & $73 \pm 10$ & $89 \pm 7$ & $86 \pm 9$ & $82 \pm 12$ & $91 \pm 7$ & 4.53 & $\checkmark$ \\
\hline$U_{s f}(\%)$ & $76 \pm 15$ & $73 \pm 8$ & $75 \pm 9$ & $74 \pm 11$ & $77 \pm 9$ & $\mid 0.58$ & - \\
\hline$E f f(\%)$ & $62 \pm 22$ & $73 \pm 11$ & $75 \pm 13$ & $73 \pm 11$ & $74 \pm 11$ & 3.77 & $\checkmark$ \\
\hline Pls (\%) & $56 \pm 21$ & $71 \pm 12$ & $72 \pm 12$ & $72 \pm 13$ & $75 \pm 12$ & 3.95 & $\checkmark$ \\
\hline Wld & $116 \pm 30$ & $109 \pm 31$ & $104 \pm 34$ & $110 \pm 46$ & $107 \pm 32$ & 0.52 & - \\
\hline
\end{tabular}

distribution of the FV_dis block has a much similar $\sigma$ as that of the prediction. However, the distribution of the FV_dis block resembles that under the individual vibrotactile cue.

\section{Conclusion}

We investigated the suitability of MLE for integrating force and vibrotactile cues. Our observations imply that MLE could play a role in integrating force and vibrotactile cues for 3D user interaction within VEs. Future work will investigate unique particularities arose from the integration of both cues.

\section{REFERENCES}

[1] J.Brown and R. Gillespie. The effect of force/motion coupling on motor and cognitive performance. Proc. IEEE WHC, pages 197-202, 2011.

[2] J. J. Braithwaite, D. G. Watson, R. Jones, and M. Rowe. A guide for analysing electrodermal activity \& skin conductance responses for psychological experiments. Psychophysiology, 49: 1017-1034, 2013.

[3] Q. Dinh, N. Walker, C. Song, A. Kobayashi, and L. F. Hodges. Evaluating the importance of multi-sensory input on memory and the sense of presence in virtual environments. Proc. IEEE Virtual Reality, pages 222-228, 1999.

[4] K. Drewing, M. O. Ernst. Integration of force and position cues for shape perception through active touch. Brain Res., 1078:92-100, 2006

[5] M. O. Ernst and M. S. Banks. Humans integrate visual and haptic information in a statistically optimal fashion. Nature, 415(6870):429433, 2002.

[6] S. Gallo, L. Santos-Carreras, G. Rognini, M. Hara, A. Yamamoto, and T. Higuchi. Towards multimodal haptics for teleoperation: Design of a tactile thermal display. Proc. IEEE ADC, pages 1-5, 2012.

[7] S. G. Hart. Nasa-Task Load Index (NASA-TLX); 20 Years Later. Proc. Annual Meeting of Human Factors Ergonomics Society, 50(9):904-908, 2006.

[8] J. M. Hillis, M. O. Ernst, M. S. Banks, and M. S. Landy. Combining sensory information: mandatory fusion within, but not between, senses. Science, 298(5598):1627-1630, 2002.

[9] R. S. Kennedy, N. E. Lane, K. S. Berbaum, and M. G. Lilienthal. Simulator sickness questionnaire: an enhanced method for quantifying simulator sickness. Int. J. Aviation Psych., 3(3):203-220, 1993.

[10] R. H. LaMotte. Softness discrimination with a tool. $J$. Neurophysiology., 83(4):1777-1786, 2000.

[11] S.J. Lederman, A. Martin, C. Tong, and R.L. Klatzky. Relative performance using haptic and/or touch-produced auditory cues in a remote absolute texture identification task. Proc. HI VE \& Teleoperation, pages 151-158, 2003.

[12] K. E. MacLean. Designing with haptic feedback. Proc. IEEE ICRA, San Francisco, CA, pages 783-788, 2000.

[13] G. Rosati, F. Oscari, C. Pacchierotti, and D. Prattichizzo. Effects of kinesthetic and cutaneous stimulation during the learning of a viscous force field. IEEE Trans. Haptics, 7(4):251-263, 2014.

[14] M. Rohde, C. J. van Dam, and M. O Ernst. Statistically optimal multisensory cue integration: a practical tutorial. Multisensory Research, 29(4-5):279-317, 2016.

[15] J. M. Walker, A. A. Blank, P. A. Shewokis, and M. K. O'Malley. Tactile feedback of object slip facilitates virtual object manipulation. IEEE Trans. Haptics, 8(4):454-466, 2015. 